\title{
Exceso de docentes y escasez de maestros La formación continua: un reto permanente
}

\author{
Ancha yaćhachikuna pishi amawtakunawan \\ Manaśhayku yaćhachina: huk imaypis atipaana
}

\section{Tojaigagantsi ogomeantatsi aike ikogiteanaka ogomeantatsi}

\section{Kara isangenaiganake mëani: iroro ikogaigi mëani ingantaigema}

Recibido: 23 diciembre 2019 Corregido: 22 abril 2020 Aprobado: 15 junio 2020

Humberto Huiza Oyola

Nacionalidad: Peruana / Filiación Institucional: I. E. "Javier Heraud" Huancavelica Correo: hhuizao@hotmail.com / ORCID: https://orcid.org/oooo-0o01-5207-8211

Abraham Ccencho Pari Nacionalidad: Peruana / Filiación Institucional: Universidad Nacional de Huancavelica Correo:abraham.ccencho@unh.edu.pe / ORCID: https://orcid.org/oooo-ooo1-7211-3715

Martha Quinto Curasma Nacionalidad: Peruana / Filiación Institucional: I. E. "Leoncio Prado Gutiérrez" Huancavelica Correo: marthacurasma@gmail.com / ORCID: https://orcid.org/000o-0003-1884-0748

\section{Resumen}

En la docencia encontramos una serie de categorías nada equivalentes entre sí, por más que se conciba como sinónimos. Estas categorías son: instructor, profesor, maestro y líder. Es crucial aclarar lo que significan cada uno de estas categorías para evitar las confusiones y evidenciar sus características y sus retos, con el propósito de elevar el nivel cualitativo de nuestra educación nacional.

\section{Palabras clave:}

Docentes, formación de maestros, formación continua.

\section{Lisichiku limaykuna: \\ yaćhachikukuna, amawtakunata yaćhachina, manaśhayku yaćhachina}

\section{Katingatsaro nibarintsipage: Ogomeantaigatsi, ikogaiganake ogomeantatsi aike irisangenaiganaje mëani.}




\section{Teacher Excess and Master Shortage Continuous Training: a Permanent Challenge}

\begin{abstract}
In teaching we find a series of categories that are not equivalent to each other, even if they are conceived as synonyms. These categories are: instructor, teacher, master and leader. It is crucial to clarify what each of these categories mean in order to avoid confusions and highlight their characteristics and challenges, in order to raise the qualitative level of our national education.
\end{abstract}

\section{Keywords}

Teachers, teacher training and continuing education.

\section{Excesso de docentes e escassez de professores A formação contínua: um desafio permanente}

\section{Resumo}

No ensino encontramos uma série de categorias que não são equivalentes umas às outras, mesmo que sejam concebidas como sinônimos. Essas categorias são: instrutor, professor, mestre e líder. É fundamental esclarecer o que cada uma dessas categorias significa para evitar confusões e destacar suas características e desafios, a fim de elevar o nível qualitativo da nossa educação nacional.

\author{
Palavras-chave: \\ Migração, fatores \\ econômicos, sociais, \\ políticos e educativos.
}

\section{Datos de los autores}

Humberto Huiza Oyola es docente e investigador en educación, ensayista y Director Ejecutivo del Instituto de Investigación, Promoción y Desarrollo Andino - IPRODEAN.

Abraham Ccencho Pari es docente e investigador en educación y ciencias sociales adscrito al Departamento Académico de Ciencias y Humanidades de la Facultad de Ciencias de la Educación de la UNH. Magister en Historia por la Universidad Nacional Mayor de San Marcos.

Martha Quinto Curasma es docente e investigadora en educación y ciencias sociales. Lic. en Ciencias Sociales y Desarrollo Rural de la UNH. 


\section{Introducción}

Partimos de la idea que el docente desempeña un rol preponderante, no sólo en la formación integral del estudiante creativo, crítico, etc., sino también en el desarrollo del país, porque la educación es el único proceso social que articula el desarrollo personal con el desarrollo social; $y$ "un maestro con desempeños de calidad supone que tenga buenas condiciones de trabajo (remuneraciones, estímulos, contexto de trabajo, etc.) y que tenga una excelente formación. La formación magisterial es uno de los factores de la calidad docente", señala Chiroque (s.f.). Pero, (se pregunta él) “¿cómo estamos en materia de formación de nuestros docentes?". Y él mismo se responde señalando que el diagnóstico revela en conclusión "serias limitaciones en el proceso formativo magisterial".

Eso indica que no todos los docentes que laboran en el sector educación son maestros.

\section{¿Quiénes son los instructores?}

Son quienes se limitan a dictar contenidos del área curricular a su cargo, sin saber por qué y para qué se deben aprender dichos contenidos, creyendo que su labor solo consiste en cumplir el horario de clases, con el mandato del director y de las normas legales que emanan las instancias superiores. Los instructores ignoran la heterogeneidad y la diversidad de las necesidades, intereses y aspiraciones de los educandos y creen que educar es transmitir información y que aprender es memorizar. No es su prioridad desarrollar la personalidad de los educandos y que estos logren aprendizajes significativos. No poseen conocimientos suficientes y dominio científico de los contenidos disciplinares. Carecen de interés por la investigación e innovación pedagógica, por la actualización permanente en los avances científicos y tecnológicos, limitándose solo hacer lo que pueden, dejando de lado lo que deben de hacer, sin tomar en cuenta las diferencias personales y culturales de los educandos.

\section{¿Quiénes son los profesores?}

Son los que conocen y dominan muy bien su especialidad y que están en constante actualización e innovación en el área curricular a su cargo. Son especialistas en alguna de las áreas curriculares. Para ello lo más importante es solo su especialidad. Ignoran o menosprecian la importancia de las demás especialidades. Apasionados por el árbol, pierden de vista el bosque. Se caracterizan por poseer un enfoque logocéntrico del proceso educativo; es decir, someten a los educandos al servicio de la información. Cuanto más conocen y dominan su especialidad, se sienten autosuficientes. Si los educandos revelan dificultades en el aprendizaje del área curricular a su cargo, creen que su nivel académico profesional es elevadísimo y piensan que no es su misión principal el dejarse entender con los discentes. Confunden la lógica didáctica con la lógica disciplinar. Igual que los instructores, tratan a los educandos como si todos ellos fuesen homogéneos. Y creen que el avance curricular es cuantitativo y no cualitativo. No evalúan a los educandos, sino califican. No sienten como prioridad la necesidad de desarroIlar las capacidades humanas en los educandos, sino solo el de transmitir mayor información. Por consiguiente, así como los instructores, tampoco saben educar. En vez de aprovechar la información que comparten con los educandos en motivo de investigación, lo convierten en un proceso extenuante y estresante. 


\section{¿Entonces quiénes son los maestros?}

Son aquellos profesionales que se diferencian de los instructores y de los profesores por su calidad humana que les permite descubrir la condición humana de los educandos y a entender que esa condición está en constante desarrollo, por el que se debe entender con respeto, responsabilidad y dedicación creativa e innovadora a esa diversidad y variedad real de los educandos, comprendiendo y aceptando que esas divergencias constituyen una riqueza cultural y no un obstáculo del desarrollo social. Por el que la misión principal del maestro no es informar los contenidos científicos del área curricular, sino formar y desarrollar la personalidad de los educandos empleando dichos contenidos científicos. El maestro no emplea en su acción educativa un enfoque logocéntrico, sino antropo-sociocéntrico; es decir, pone los conocimientos al servicio de los educandos y no al revés. Y es consciente de lo que no se puede educar a quien no se conoce. $Y$ conocer a los educandos no equivale solo a saber sus nombres y apellidos, a conocer su estatura y contextura, el color de su piel y de su cabello; es decir, sus características somáticas.

Para el maestro conocer los educandos significa descubrir y entenderlos transdisciplinariamente. Esto es: conocer antropológica, sociológica y psicológicamente. Vigotsky (1979) no en balde señaló que "el hombre es cultura internalizada" y Aquedas (1986) reveló una gran verdad: "Hay una relación directa entre el medio ambiente y la cultura humana". Lo que explica que, por la heterogeneidad de nuestro medio ambiente nacional, nuestras culturas que en él se desarrollan no son homogéneas. Por el que la misión del maestro es investigar y conocer estas diferencias culturales para que pueda educar con acierto a los educandos.

El conocimiento sociológico permite identificar el sector o la clase social de donde proceden los discentes, porque su procedencia determina y sustenta la naturaleza de sus necesidades, intereses y aspiraciones socioeconómicas, políticas y culturales. Y estas condiciones sociales son las que se reflejan en la vida psíquica de los educandos. Su desconocimiento impide lograr todo tipo de aprendizaje significativo. Para que los educandos logren aprendizajes significativos, es fundamental que el maestro conozca científicamente el desarrollo de cada uno de los procesos psíquicos (tanto los procesos cognitivos como los procesos mentales), las condiciones en las cuales estos se desarrollan y el tipo de actividades que permiten dicho desarrollo.

Además de conocer antropológica, sociológica y psicológicamente a los educandos, el maestro es quién conoce la Historia de su país, su realidad económica, política y jurídica, además de conocer la Pedagogía y su propia especialidad. Por el conocimiento de la Historia de su país sabe a qué sociedad pertenece, de cuál es su identidad cultural, de dónde viene y hacia a dónde va y de cuál es su rol en dicho proceso histórico. El conocimiento de su realidad económica le permite no ahogar a los educandos en una exigencia vacía y estéril y a formar para el empleo productivo. El conocimiento de su realidad política orienta su actividad pedagógica, aclarando los objetivos que debe lograr, los fines que debe conseguir y las metas que debe alcanzar. Los maestros no son apolíticos. La política del maestro es descubrir y compartir la verdad, la belleza y la bondad; es decir, contribuir en el desarrollo científico, estético y ético de la sociedad, procurando que estos conocimientos científicos se traduzcan en tecnología para mejorar y elevar el nivel de calidad de vida de la sociedad y de las diversas formas de la actividad social. El conocimiento de la jurisprudencia le faculta defender sus derechos laborales, profesionales y gremiales, así como asumir la defensa de los derechos de sus educandos y a cumplir con su deber. Si no sabe defender sus derechos y los de sus educandos, no es maestro. Tomando en cuenta las cualidades de la personalidad que a un docente eleva a la categoría de maestro, señalamos que en nuestro país hay escasez de maestros y exceso de docentes. 
$Y$ es fundamental entender que ser maestro no significa estar resignado a lo último que nos depara el destino, sino es un compromiso con lo mejor que puede haber en la vida: forjar el futuro de nuestro país a partir de la formación y desarrollo polifacético de los educandos, porque sin el hombre no hay ninguna carrera profesional, no hay desarrollo económico, social, político, cultural, científico y tecnológico. Para conseguir el desarrollo familiar, institucional, local, distrital, provincial, regional, nacional e internacional, es vital la formación y el desarrollo de la personalidad de los hombres. Es inconcebible el desarrollo de un pueblo y de un país sin el desarrollo de su población. Motivo por el cual, el sector educación merece todo el respeto del caso y no el menosprecio. Quién menosprecia al sector educación menosprecia la formación y el desarrollo humano y a la vez revela su inepcia intelectual para entender su esencia social y su rol en el desarrollo de su pueblo y país. Quién menosprecia al maestro, menosprecia su propia formación intelectual, por consiguiente, se menosprecia a sí mismo. Es decir, revela su carácter despreciable.

Sin embargo, no todas las universidades que otorgan el grado de maestría a quienes se gradúan en dicho posgrado garantizan que todos sus egresados sean realmente maestros. Dichas maestrías son, en la mayoría de los casos, más que un grado académico, un grado burocrático, conocida por el pueblo como "maestrías chicha". No cualifican ni garantizan la trascendencia profesional y humana de sus egresados. En vez de depurar en ellos todo signo de huachafería, los convierten en personas cursi; una de las causas por las que no hay una educación de calidad, inspiradora de confianza en la formación de buenos ciudadanos que sepan asumir responsabilidades en la solución de problemas que aquejan a nuestra sociedad.

Pero no solo están los instructores, profesores y maestros en el sector educación; sino también están los refugiados, los ganapanes, que tanto daño hacen al magisterio nacional y a la educación de nuestros niños, niñas, adolescentes y jóvenes. Ellos van a las instituciones educativas cuando quieren, hacen clases cuando pueden y son remunerados por destruir la reputación del maestro y el futuro de nuestro pueblo y de nuestro país, al amparo de la corrupción de nuestras "autoridades" de las UGEL y de las DRE. Allí otra de las razones para que nuestro sistema educativo esté en crisis.

Son muchos los docentes que se han incorporado a la Ley de la Carrera Pública Magisterial (LCPM) de la Ley del Profesorado (LP), antes de la promulgación de la Ley de Reforma Magisterial, seducidos por la promesa de una buena remuneración y aventados a la pobreza económica en que vive el magisterio nacional, y han conseguido mayor remuneración de lo que percibían anteriormente. Pero esta mejora salarial no se ha traducido directamente en un mejor desempeño laboral. Los buenos decentes de la LP al incorporarse a la LCPM, lo seguían siendo buenos o casi buenos; y los malos, seguían siendo malos, incluso muchos de ellos han empeorado su desempeño laboral.

Y no es cierto que todos los que se han incorporado a la LCPM han sido los mejores docentes. Solo fueron los que han alcanzado el puntaje que exigía dicha incorporación. Y muchos de ellos han echado mano de las estrategias más sórdidas y oscuras que les fueron posibles para lograr dicho propósito. Tampoco la evaluación fue consistente ni confiable. ¿Por qué? Porque muchas instituciones educativas carecen del CONEI, de esa instancia responsable que tiene la misión de evaluar y otorgar constancias de desempeño laboral a quienes solicitan, por el que muchos han inventado constancias de su desempeño laboral con calificativos de excelente, sin que se merezcan.

En las instituciones educativas, muchos directores que pertenecían a la LCPM, teniendo carga horaria, no hacían clases; ni realizaban gestiones, ni por último cumplían con su misión 
de dirigir la institución a su cargo. Por el contrario: medraron a costa de los ingresos propios de la institución. Ocurrió igual con la mayoría de los docentes de la LCPM. No desarrollaban sesiones de aprendizaje de calidad, sino sesiones de aburrimiento. $Y$ lo han convertido en un rito: más actividades de extensión (tareas) para la casa, menos sesiones de aprendizaje en el aula, sin que les importe la salud mental de los educandos, generando en ellos mayor depresión y estrés. Esto evidenció categóricamente que los malos docentes de la LCPM no tenían compromiso con la formación y desarrollo de los educandos. Al contrario, muchos de ellos han convertido la institución educativa en un mercado donde se vende información a sobrecosto (copias); en un mercado donde se venden los puntajes de evaluación para que los educandos sean promovidos de un grado a otro, según sus posibilidades económicas y no en razón del desarrollo de sus capacidades intelectuales, evidenciando que donde reina el dinero no hay educación; sino casi siempre la mayor corrupción.

Está demostrada que la crisis educativa es un problema de carácter multifactorial. No hay duda en que el problema es de carácter: económico, social y político. Pero, entre todos estos factores, el factor gravitante es el factor docente como el sujeto principal del componente social. No solo es el factor económico. Ni un instructor, ni un profesor, por más buena remuneración que perciban, podrán revertir estas crisis educativas si no llegan a ser maestros. Esto ya está demostrado por la aplicación de la LCPM.

Empero, la crisis educativa no es solo un problema nacional, sino internacional, tal como consta en el siguiente cuadro 1:

\section{Cuadro 1.}

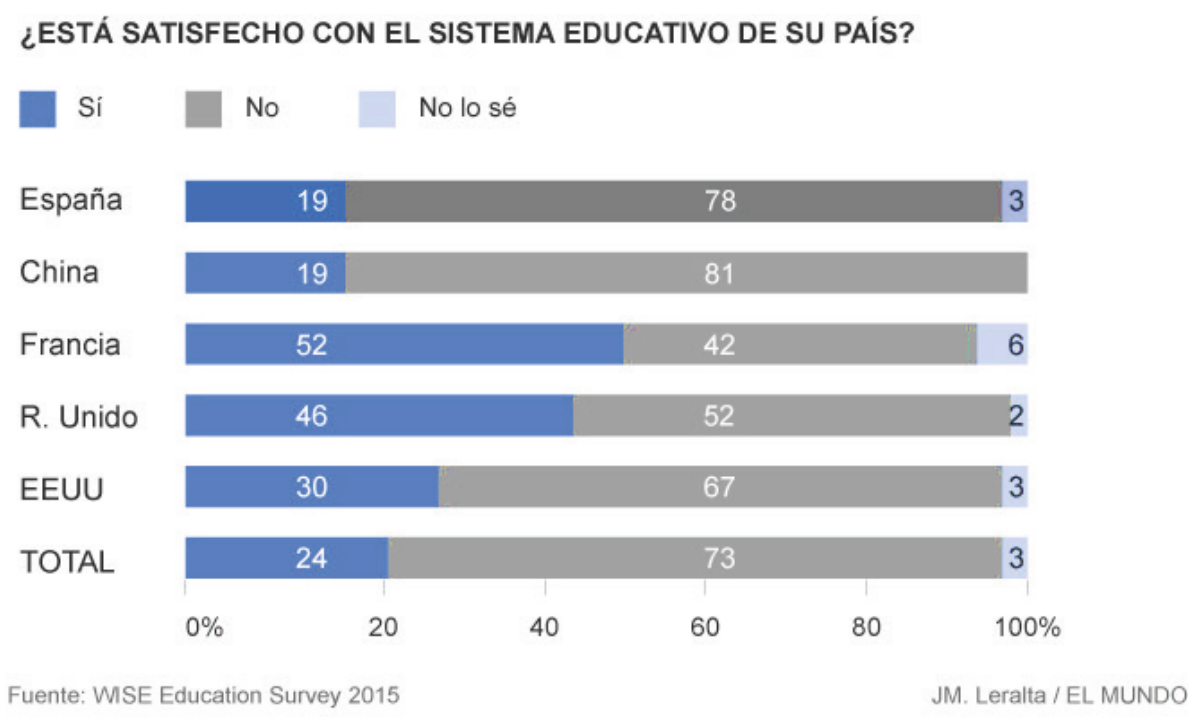

Fuente: Sanmartín (2015). Los cinco grandes problemas del profesorado español.

Esto demuestra que "La educación está desconectada del mundo real y su mayor problema es la falta de calidad del profesorado" (Sanmartín, 2015). Esta situación, al generar un movimiento de preocupación nacional e internacional, ha dado lugar a la realización de muchos seminarios, cursos, capacitaciones, especializaciones, foros, debates, encuentros y congresos 
sobre la crisis educativa y sus alternativas de solución, generando como resultado una abundante información. Sin embargo, toda esta riqueza cultural, producto de tantos eventos, aún continúa al margen de los procesos educativos que se realizan en las aulas. Pues así indica nuestro sistema educativo que no presenta signos de mejoría. Por el que es necesario y fundamental actualizar y cualificar a los docentes que están en las aulas hasta convertirlos en maestros; en maestros innovadores, protagonistas de la transformación de la crisis educativa en creces educativa. Esta cualificación, necesariamente tiene que sustentarse en la formación continua de los docentes, que cuya finalidad debe ser lograr los siguientes objetivos:

a) transformar a los docentes de recogedor de papeles en investigadores y productores de conocimientos pedagógicos.

b) transformar la convicción de los docentes de solo trabajadores en el sector educación en la convicción de trabajadores profesionales para el desarrollo del país.

c) convertir la formación y desarrollo de la personalidad de los educandos como el eje central del proceso educativo, para que este deje de ser un simple reflejo de la crisis estructural; $y$

d) reivindicar el prestigio profesional, que con justicia le corresponde al maestro como forjador del futuro, con reconocimiento económico permanente por parte del Estado.

Esta formación continua debe estar a cargo de las instituciones y de los intelectuales más idóneos, que cuya trascendencia moral y científica gocen de confianza por la calidad del impacto de sus experiencias innovadoras y exitosas.

\section{De recogedor de papeles a investigador y productor de conocimientos pedagógicos.}

A consecuencia de la corrupción muchos docentes se han convertido solo en recogedor de papeles. Pues hay corrupción en el nombramiento y contrata de docentes y administrativos; en el nombramiento y encargatura de los cargos directivos y en los ascensos de nivel. El sistema de evaluación no despierta ni garantiza ninguna confianza en sus resultados. Cuando la evaluación es de conocimientos, no en pocas ocasiones, la clave de las pruebas escritas ya están siendo negociadas con anterioridad; cuando la evaluación es del currículo vitae, los diplomas, los certificados, las constancias y las resoluciones de actualización, especialización y felicitación son falsificados con total descaro que permite la impunidad; si la evaluación es del desempeño laboral en el aula, los interesados o bien sobornan a los jurados o se preparan todo lo mejor que puedan solo para impresionar ese día. Como ha constatado Crisólogo (1995):

las evaluaciones a las que son sometidos (los docentes), para lograr una plaza en el Ministerio de Educación, para acceder a una cátedra universitaria, para ascender, etc., se basan, en un gran porcentaje de veces, en evaluación de documentos. Esta situación ha generado una fiebre por obtener papeles. Frente a esta necesidad, ha surgido un mercado que tiene dos caras, propio de un sistema social en descomposición: una cara simpática y otra grotesca. La primera configura la oferta de eventos serios, ofrecida por instituciones serias, como universidades e instituciones que cuidan su prestigio; y la otra cara está dada por el mercado negro, en el que medran instituciones que se han dedicado ofrecer cursos sin ninguna calidad. En este negociado están involucradas, lamentablemente, algunas instituciones universitarias, ONGs y otras fantasmas, que usan el logotipo de organizaciones educativas respetables. Se ofrecen cursos para todos los gustos, cursos llamados de actualización, de capacitación, de complementación universitaria, de Segunda Especialidad, diplomados, hasta maestrías y doctorados, 
y que adoptan diferentes modalidades, producto del ingenio de la viveza criolla, los que se reducen, en el mejor de los casos, a distribuir unas separatas de dudosa calidad académica, unas cuantas charlas presenciales, desarrolladas por personas carentes de la preparación académica indispensable para este fin; en otros casos ni siquiera eso, basta con abonar el valor del evento y recibir el certificado (p. 35).

Los resultados indignantes de esta corrupción no quedan lejos de las instituciones educativas ni de las aulas. Llegan hasta allí donde los niños, niñas, adolescentes y jóvenes esperan ansiosos por adquirir nuevas sabidurías y los convierten en sus víctimas, arrasando en ellos todo signo ético y moral. Si son docentes, venden notas; multiplican el costo de las fotocopias. Si son directores, negocian con los certificados y con las plazas de contrata, se apropian de los ingresos propios o de los presupuestos de mantenimiento institucional. Imponen el pago por la ley del derecho de piso a los docentes y administrativos nuevos. Creen que su profesión y su cargo es un negocio y la institución educativa, un mercado; en el que el proceso educativo debe regularse por la ley de la oferta y la demanda. Su lenguaje cotidiano no es ético ni pedagógico, sino coprolálico, venal, infame y patológico. La educación no es un tema que les importa en el dialogo, sino el sexo y el alcohol.

Esto evidencia que en nuestro país no hay educación superior como sistema sino solo la denominación y no siempre son los docentes más idóneos los que aprueban la evaluación, sino casi los que siempre apuestan por la corrupción. Allí la prueba de que las "autoridades" que constituyen la comisión de nombramientos, contratas y ascensos de nivel, en su gran mayoría, no son personas respetables por su dudosa formación y trayectoria ética y moral, por su nula responsabilidad profesional y su escaso compromiso con el desarrollo del país. Esto demuestra que la especialidad de muchos de ellos no es sino la obscenidad y la cleptomanía; su obsesión no es sino el de ser dipsómanos y, ansiosamente, cursis, por eso son sus rasgos distintos la presuntuosidad, la petulancia, el abuso y la gandulería. Y su influencia negativa en el proceso educativo es irrefutable e inocultable. La necesidad de cambiar esta situación urge de una nueva política de evaluación del magisterio. Para el nombramiento, contrata y ascensos de nivel, el trabajo de investigación y de innovación pedagógica, por lo menos con una trascendencia local, debe de ser el principal requisito de mayor puntaje. Solo así se puede transformar a los docentes de recogedor de papeles en verdaderos y auténticos maestros investigadores, en productores de conocimientos pedagógicos e innovadores, en personas capaces de constituirse en ejemplos de la posibilidad de cambio, de lo que es posible ser cada día mejor y en mensajeros de la esperanza de un futuro más digno, más justo y más humano.

Y no es cierto que todos los egresados de "educación superior" ya están premunidos de nuevos conocimientos pedagógicos actualizados y que pueden desempeñarse como educadores en cualquier lugar del ámbito regional o nacional, sin ningún problema; porque el título profesional no es siempre garantía de calidad profesional. El anhelo por iniciar a trabajar en las zonas urbanas que en las zonas rurales es un indicador de que no están preparados como para transformar realidades adversas. Este anhelo revela y testimonia la deficiente formación científica y el escaso compromiso profesional que han recibido en las universidades y en los institutos pedagógicos. ¿Por qué? Por dos razones fundamentales:

Primero, porque los conocimientos que se adquieren en las aulas universitarias y en los institutos pedagógicos, en su mayor porcentaje, no son conocimientos científicos muy bien sistematizados que permiten descubrir y comprender la naturaleza de la situación problemática del contexto donde se va laborar. Son informaciones sueltas, generales, superfluas, unilaterales, especulativas y ajenas a nuestra realidad. Es verdad que un maestro tiene que conocer la 
realidad internacional, nacional, regional y local y el rol que le toca cumplir. En ese sentido es una necesidad que conozca las siguientes ciencias: Antropología, Sociología, Psicología, Neurología, Historia, Economía, Geografía, Política, Lingüística, Semiótica, Pedagogía y Filosofía por formación general, además de su especialidad y que esté muy bien actualizado en cada una de ellas. Pero no debe quedarse solo en esos conocimientos. Lo fundamental, además de todos estos conocimientos, es conocer a los educandos. No es suficiente para educar saber con qué y en qué educar; sino saber a quién y para qué vamos a educar, dónde y cómo.

Segundo, porque la realidad de nuestra región y de nuestro país no es homogénea, sino diversa y variada; donde los mismos problemas no tienen la misma relevancia en cada contexto geográfico, económico, social, lingüístico y cultural. Por ende, esta diversidad problemática no requiere de una solución, sino de una diversidad de soluciones. Y estas soluciones solo son posibles en base a la investigación pedagógica desarrollada en cada contexto particular que permite el conocimiento de la situación concreta. Los problemas son concretos y no abstractos. Las soluciones también tienen que ser concretas y no especulativas. ¿Cuánta investigación de campo desarrolla nuestras universidades y nuestros institutos pedagógicos? Si hay investigación de campo, ¿con qué seriedad la desarrollan? Allí el problema.

Es importante volver a recordar lo señalado por el antropólogo Arguedas (1986): "hay una relación directa entre el medio ambiente y la cultura humana" (p. 137). El ser humano se desarrolla en función de la necesidad y de los recursos con que cuenta en su medio geográfico. Cuantas más necesidades tiene, aunque suene paradójico, se desarrolla más. Si tiene menos necesidades, se desarrolla menos. Esto está demostrado por la Historia. La cultura es lo que hace el hombre con lo que tiene y la forma cómo lo hace. También hay que volver a recordar que Vigotsky (1979) señaló: "el hombre es cultura internalizada". Esto hace que los pueblos difieran de un piso a otro piso ecológico, generando actividades económicas y relaciones sociales, en el contexto mayor de la formación económico-social, diversas. Para responder pedagógicamente a esta diversidad hay que investigar y estudiarla científicamente. Entender que en cada educando hay una cultura, producto de la interacción social que se da en su contexto. Y educar no es destruir esa cultura, sino enriquecerla y desarrollarla. Lo contrario no es educación, es alienación; en lugar de respetar es destruir la identidad del educando. Una persona sin identidad pierde el sentido de su existencia, carece de dignidad humana, vive según la "suerte" no según su capacidad; cree que la desgracia en que vive es natural e inevitable y no el resultado de la injusticia social que se puede y se debe evitar y/o transformar. Esto es: educar es formar y desarrollar la personalidad de los educandos para que puedan ser capaces de entender sus diferencias como una riqueza que les permite crecer y no como un obstáculo que impide la unidad social y cultural; teniendo en cuenta que la condición humana es la que nos une a todos.

\section{De simple trabajador a trabajador profesional en el sector de educación.}

Tenti (2005), consultor de la Unesco en Buenos Aires, señaló, refiriéndose de los docentes: "ellos no son profesionales en el sentido clásico de la expresión. Ellos no son "propietarios" de los medios que utilizan para desarrollar su trabajo, sino que lo hacen "en relación de dependencia". Como tales, son funcionarios de un sistema educativo de gestión estatal o privada. Desde este punto de vista se pueden definirse a sí mismos (y de hecho lo han hecho) como "trabajadores" y no como profesionales" (p. 34). Esta evidencia que nos presenta Emilio Tenti Fanfani nos recuerda la real situación desprofesionalizada de muchos docentes. 
El sentimiento de dependencia burocrática despoja y destruye toda vocación pedagógica, desalienta toda iniciativa innovadora, confina a la resignación, vulnerando la dignidad profesional. Cuando el docente, sea profesor o licenciado, profesora o licenciada, no se siente profesional sino un trabajador dependiente de un jefe inmediatamente superior, su objetivo de educar a los educandos se diluye para dar lugar a un objetivo subalterno: complacer a los jefes. Esta confusión de los objetivos no solo daña al sistema educativo, sino a la esencia de la propia profesión docente.

En un sistema educativo en crisis, donde los jefes reinan en función de sus caprichos, buscando sus comodidades personales a costa de las expectativas y de la generosidad de los estudiantes y padres de familia, complacer a los jefes y estar de su lado significa estar inmersos en la corrupción. Y esta sumisión, inobjetablemente, desprofesionaliza al docente, convirtiéndolo en un simple trabajador que cuya situación laboral transcurre al filo de la inseguridad. Los docentes desprofesionalizados no trabajan en función de su profesión, sino en base a la sumisión burocrática y en complicidad con los actos ilícitos que cometen los jefes.

Las instituciones educativas y sus instancias superiores, llámese UGEL, DRE y el propio Ministerio de Educación no necesitan jefes, sino maestros y líderes. Nuestro país requiere de personalidades con liderazgo profesional para emanciparnos de la anomia social. Es misión de nuestras instituciones educativas formar esas personalidades con liderazgo. Por el que los docentes, los directivos y los especialistas tienen que ser líderes y no jefes. Este liderazgo es imposible sin el conocimiento de nuestro país, sin la convicción de que la vida de todo profesional solo es trascendente cuando está al servicio de la sociedad y sin que se sepa que la construcción del futuro de nuestro pueblo, de nuestro país y de la humanidad en su conjunto, solo es posible desplegando la capacidad crítica y creativa, ética y moral.

El que los docentes se definan a sí mismos solo como trabajadores y no como profesionales en la educación repercute negativamente en la labor educativa. El hecho de sentirse solo trabajador y no un trabajador profesional, es sentirse ajeno a la problemática institucional, a los destinos de la localidad y del país; es sentirse solamente comprometido con el jefe. Es verdad que el docente no es un profesional liberal, sino un profesional dependiente. Pero esta dependencia profesional no está relacionada directamente de la existencia de alguna jefatura, sino de su capacidad profesional de formar y desarrollar capacidades humanas en los educandos; de su capacidad de forjar el futuro de la sociedad a través de la formación de nuevas generaciones.

El de sentirse solo un trabajador asalariado, que cuya labor se impulsa no en función de una vocación pedagógica, sino en razón de una necesidad y de una obligación económica, es una evidencia de una opción fatal: el del suicidio profesional. Y su labor se caracteriza por lo siguiente: a mayor control por parte del director, mayor puntualidad por parte del docente; a mejor remuneración, mayor compromiso con el director. Si el director no controla y la remuneración no cubre sus expectativas, una apatía laboral. Y esto es lo que está ocurriendo generalmente.

El rasgo distintivo de un profesional es el ejercicio de su especialidad, es el conocimiento científico y dominio metodológico para resolver los problemas de su responsabilidad. $Y$ un profesional sabe que su competencia laboral depende de la investigación científica que realiza. Sabe que, con mayor y mejor conocimiento, con mayor y mejor ejercicio profesional, puede conseguir mayores y mejores condiciones laborales, mayores y mejores remuneraciones. Sabe que el origen del hombre fue antes que el origen del dinero; sabe que el conocimiento 
científico y su aplicación tecnológica es cada vez más creciente y permite transformar la naturaleza y satisfacer las múltiples necesidades humanas. Por consiguiente, la comprensión de esta realidad permite profesionalizarse de manera permanente, de manera independiente, fortaleciendo la vocación por una vida mejor.

Es verdad que nuestro contexto educativo nos presenta solo más trabajadores dependientes que trabajadores profesionales independientes. Los docentes dependen del director. El director depende del azar de las circunstancias, sino depende de las directivas de la instancia superior. La gran mayoría de las instituciones educativas carecen de dirección. Pues la dirección no es solo el cargo ni la oficina en la que atiende la persona que ejerce dicho cargo. La dirección es mucho más que un cargo y una oficina. La dirección implica capacidad de conducción institucional y no capacidad de inercia o de destrucción institucional. Muchos "directores" ni siquiera saben elaborar los informes laborales de su institución para remitir a las "instancias superiores", quienes lo hacen en vez de ellos son las secretarias o algún docente contratado con ese propósito específico; solo son campeones en la informalidad y en la corrupción. Todas estas características no solo evidencian la crisis educativa que padece el país, el curso devastador de la anomia social, los preocupantes defectos de la formación de la personalidad y una serie de patologías endémicas, sino fortalecen la crisis educativa convirtiéndolo en un factor desintegrador de la sociedad.

Esta situación nos evidencia que otra de las causas principales de la crisis educativa es la desprofesionalización del docente el de reducirse a la condición solo trabajadores en la educación, a sabiendas de que cualquiera puede ser trabajador en la educación. Una persona analfabeta también puede trabajar en la educación, asumiendo que la educación es todo es todo lo que se hace en la institución educativa. Una persona analfabeta puede desempeñarse sin ningún problema como personal de limpieza y de guardianía. Una persona sin ser profesional también puede dictar la clase y para dictarla solo necesita saber decodificar fonéticamente muy bien el texto. Cualquiera puede llevar textos fotocopiados, plumones y papelotes y distribuir a los educandos para que ellos puedan resumir o esquematizar en los organizadores de conocimiento los contenidos del texto y ver como ellos exponen y luego recoger dichos materiales para calificar. Para realizar estas actividades no se necesita ser profesional y estar actualizado. Basta con la capacidad de cumplir las horas y ser amigo del director.

Ser un trabajador profesional en la educación es una realidad diferente. Cualquiera no puede ser un trabajador profesional en la educación. Es un profesional de triple vocación: a) su gran vocación es contribuir a la forja de un futuro más humano; b) es convertir de cada individuo en una personalidad; de cada cerebro, en conciencia social; y c) tener pasión por la investigación científica para compartir sus avances y sus logros con los demás en una determinada disciplina científica. Un trabajador profesional en la educación no dicta clases, sino forma personas, desarrolla y multiplica capacidades humanas, consciente de que su labor está forjando el futuro y no está justificando su mera existencia con actividades difusas e intrascendentes. Es una persona que con su sola presencia inspira cambio, respeto, admiración y dignidad. No es una persona incoherente con lo que dice y con lo que hace. No es una persona que trabaja en función de las directivas de un jefe, sino en función de la solución de los problemas concretos; no es una persona que busca trascender poniéndose al frente de los demás; sino una persona que trasciende escuchando y canalizado las necesidades, intereses y aspiraciones de sus educandos; buscando la solución a sus problemas; buscando nuevos horizontes a sus expectativas; nuevas energías a sus debilidades; nuevas esperanzas a sus frustraciones, ayudando a convertirse a cada educando en el autor principal de su destino y no en el protagonista de un libreto ajeno. 
Formar y desarrollar la personalidad de los educandos es formar y desarrollar la capacidad intelectual, afectiva y volitiva de los futuros ciudadanos. Informar no es educar. No es maestro el que se limita solo a brindar información. El maestro no puede ni debe reducirse a la condición de solo el libro, CD, USB, DVD o Internet. Estos instrumentos tecnológicos tienen la gran capacidad de almacenar, conservar y trasmitir tanta información. El maestro es mucho más que todos estos medios. Es un ser humano que cuya misión fundamental es formar seres humanos y no un instrumento tecnológico que solo sirve para transmitir información. Para el maestro, la información es un medio y no un fin. La tecnología es un recurso educativo y no el sujeto de la educación.

Por el que, para revertir la crisis educativa, nos urge contar con más trabajadores profesionales en la educación y esto demanda profesionalizar a los trabajadores en la educación. Esto es: convertir en alguien a los que hoy en día son o se sienten cualquiera. Es una demanda social que los docentes se conviertan en maestros y líderes de formación y desarrollo humano y que reivindiquen la buena reputación profesional. Lograr aquello es imposible sin dejar de lado la rutina, abandonando la formación de las capacidades profesionales que permitan el desarrollo de la autonomía intelectual: sustento de una educación de calidad.

\section{De una educación recreadora de la realidad hacia} una educación transformadora con liderazgo pedagógico.

No es misión de la educación reflejar y/o reproducir la crisis económica, social, política y cultural que sufre el país como su contexto inmediato y su referente directo; sino formar y desarrollar la personalidad de los educandos para que puedan transformar esta situación. Wiener (2011) dijo con respecto a la prensa: "no somos reflejo de lo que la gente piensa, sino formadores de opinión". Y los docentes deben decir lo mismo que nuestras instituciones educativas no son reflejos de las carencias y frustraciones de nuestra población, sino un centro de formación de líderes, de artistas e intelectuales para que puedan transformar esta realidad y forjar un futuro mejor.

El trabajo del maestro no debe consistir tan solo en transmitir información, ni siquiera de conocimientos, sino en presentarlos en forma de situación problemática, situándolos en un contexto real concreto, de manera que el educando pueda establecer el nexo entre las interrogantes de mayor alcance y sus posibles alternativas de solución. La acción pedagógica debe lograr el pleno desarrollo de la personalidad del educando respetando su autonomía; y la autoridad de la que están investidos los docentes debe de fundarse en el libre reconocimiento de la legitimidad del saber, como recomienda el informe Delors (1997). Esto implica que el maestro tiene que transformar en liderazgo su misión profesional.

Y ser maestro líder significa ser capaz de planificar, organizar y dirigir la sesión de aprendizaje buscando que todos los educandos sean partícipes del beneficio que ella genera. ¿Qué significa planificar? Definir los objetivos, escoger los métodos, seleccionar los recursos y las técnicas a emplearse, las formas de organización educativa que permita lograr los objetivos y prever las condiciones de su ejecución: tiempo y espacio. De la misma forma implica determinar las estrategias, instrumentos y los criterios de evaluación. ¿Qué significa organizar? Significa articular la secuencia de las actividades educativas, con todos los recursos que se 
ha planificado en función de los objetivos que se busca lograr, tomando en cuenta el espacio y el tiempo en los cuales se ha de ejecutar la sesión educativa. ¿Qué significa dirigir la sesión educativa? Significa conducir y guiar a los demás en función de la actividad planificada y organizada, regulando y controlando todo el proceso educativo (teoría y práctica) para garantizar el logro de los objetivos previstos. ¿Cuáles son los requisitos para ser un maestro líder? Son los siguientes:

- Visión de futuro: el maestro líder ve más allá de lo que está delante de sus ojos, ve las potencialidades de lo que pueden llegar a ser los educandos gracias a la educación de su imaginación, de sus sueños, de su habilidad y de su perseverancia. Para el maestro líder un papel en blanco puede convertirse en una revista o en un libro; una piedra, en una estatua, en una obra de arte; un tacho de basura, en un centro de reciclaje; la pobreza de un pueblo en una motivación de éxito laboral, social e intelectual; un país pobre en un país rico; los niños y niñas en científicos, tecnólogos y artistas que la comunidad demanda para su desarrollo. No hay maestro líder sin visión de futuro.

- Imaginación y creatividad: son dos elementos claves para desarrollar la visión de futuro de los maestros líderes. Los japoneses, después de la segunda guerra mundial, gracias a la imaginación y a la creatividad, volvieron a convertirse en una potencia mundial, incluso superando a los norteamericanos, siguiendo la consigna de: imitar, igualar y superar. En cambio, los estadounidenses, privilegiando la lógica y la exactitud, lo habían reducido toda su posibilidad de desarrollo a lo alcanzable de manera inmediata. Los líderes tienen que aplicar los conocimientos con imaginación y creatividad en la práctica para transformar la realidad en el bienestar de todos.

- Humildad para aprender: el maestro líder es consciente de que no lo sabe todo y no lo puede saber todo. Su misión es aprender y ayudar a aprender. Aprender es comprender, organizar y manejar la información aplicando las capacidades intelectuales de carácter cognitivo. El líder observa, escucha y reflexiona; es decir, no actúa mecánicamente. Es una persona que sabe preguntar con sencillez y sinceridad para saber lo que su interlocutor sabe. No pregunta para calificar, sino para aprender.

- Mayor responsabilidad: la gran misión del maestro líder es formar nuevos líderes ofreciéndoles oportunidades para que ellos mismos descubran su rol en la vida y forjen su visión de futuro y se lancen a descubrir las maravillas del mundo, procurando que su mirada trascienda las fronteras de la rutina, a buscar el bienestar de todos transformando la realidad. El maestro líder enseña la libertad humana, diferenciando de la libertad animal. La libertad animal consiste en hacer lo que se puede y lo que se quiere. Mientras la libertad humana consiste en hacer lo que se debe y en hacerlo bien.

- Sensibilidad social: el maestro líder es capaz de sentir lo que otros sienten y de escuchar lo que otros piensan. Es como la antena satelital que registra la preocupación de su tiempo histórico y de su espacio social. Es capaz de identificar y diferenciar lo positivo de lo negativo y de multiplicar el optimismo hasta convertirlo en una energía transformadora de la realidad, de acuerdo a los objetivos que se busca. No es una persona indiferente ni abúlica. Es una persona que siempre ve en todos cierta cualidad. Si no los hay, si las inventa hasta convertirlas en realidad.

- Optimismo y esperanza: el maestro líder posee un optimismo inquebrantable, no es un pesimista. Él ve, donde hay un problema, una oportunidad. El pesimista ve delante de una 
oportunidad un obstáculo. Cuentan que la UGEL envió a dos maestros a la zona rural. Una semana después llamó uno de ellos y dijo al director de la UGEL: "señor, es un fracaso, aquí nadie sabe leer ni escribir". Al rato llamó el otro y dijo: "señor, aquí tengo una magnífica oportunidad de mi éxito profesional, pues nadie tiene sabe leer y escribir". El optimista piensa: aquí nadie sabe leer ni escribir, yo voy a prestarles un gran servicio haciendo que los aprendan. Ellos van a ganar, mi pueblo va a ganar y yo voy a ganar.

- Libertad y autonomía: el maestro líder no genera dependencia. Forma personas libres y autónomas. Es una persona con autoridad, porque permite crecer a los demás. Autoridad proviene del griego "ugeo" que significa "hacer crecer". Sin embargo, si queremos a otros tenemos que estar dispuestos a ser guiados por quienes poseen la sabiduría. La sabiduría no es propiedad privada de profesionales, intelectuales o de líder. La sabiduría es la síntesis de saber mirar con el corazón y la razón. El maestro líder tiene que hacer el esfuerzo por desarrollarla y si no la posee, escuchar a quienes la tienen.

- Empatía y solidaridad: la empatía es la capacidad de sentir lo que el otro siente, es la base de la solidaridad. Sin empatía es imposible la solidaridad. El maestro líder es esencialmente la persona con capacidad de ponerse en el lugar del otro, el que es capaz de sentir lo que siente su interlocutor y el que es capaz de sacarlo de su dolor, de guiarlo hacia la libertad; es la persona que posee talento para hacer que cada uno de sus seguidores se sienta importante, es el que otorga el más alto significado a cada persona, es el que hace sentir a cada uno un ser especial, único, querido y aceptado; es el que reconoce las limitaciones personales, económicas o familiares de los demás y el que los recibe para hacer crecer en todas sus potencialidades humanas.

- Enseñar con ejemplo: las palabras convencen y mueven; el testimonio arrastra. Solo se sigue con auténtica pasión a quien es coherente con lo que siente, con lo que piensa, con lo que dice y con lo que hace. El enemigo mortal de un líder es su propia incoherencia. Liderazgo es compromiso y congruencia con los valores. Los líderes se hacen líderes porque promueven valores fundamentales que responden a las necesidades de sus seguidores. Martin Luther King ordenó toda su vida en función de la igualdad, Gandhi en función de la independencia, Nelson Mandela en función del respeto por la gente de su raza, Túpac Amaru en función de la libertad, César Vallejo en función de humanismo, etc. Todos ellos eran capaces de sacrificar su vida en función de esos valores.

- Capacidad de investigación permanente: ser maestro líder significa estar siempre en búsqueda de nuevas informaciones, de nuevos conocimientos; estar en permanente renovación. La lucha de un maestro líder es un compromiso con el tiempo, lo cual requiere de una gran energía. El líder es aquel que cuando se cansa, se desanima o se distrae, tiene la capacidad para reflexionar y volver a sus ideales para salir más fortalecido y comprometido con su misión. No hay líder que no conozca su realidad, que no conozca en amplitud y profundidad.

- Ser hombre de fe: un maestro líder sin fe en sus educandos y en su pueblo es como un ave sin alas: no puede volar. Es la confianza en que sus objetivos serán alcanzados la que le impulsa permanentemente. Toda acción conlleva posibilidades de éxito o fracaso. El maestro líder es el que cree contra toda razón que tendrá éxito en su misión. Su fe lo convierte en un ser tenaz y perseverante. Tenacidad no es terquedad. La tenacidad es visionaria, la terquedad es ciega. La terquedad obnubila la razón, la tenacidad la aclara. La terquedad no se deja aconsejar ni criticar, la tenacidad está abierta al dialogo, a la crítica y al cambio de 
rutas. La tenacidad se deja enseñar, la terquedad solo quiere enseñar y conducir, no aprender. La tenacidad es sabia, la terquedad es necia. Por eso el libro de los Proverbios en la Biblia dice: "critica al sabio y se hará más sabio. Critica al necio y te lo echarás de enemigo". El líder es un ser tenaz que posee una profunda fe en que las personas y los hechos pueden cambiar si se trabaja con pasión y entrega, hasta lograrlo.

- Comunicación eficaz: el maestro líder solo es tal en la medida en que es eficaz en transmitir sus ideas, sentimientos, deseos y sueños a los demás, en la medida en que es capaz de persuadir con eficiencia. Esto implica capacidad comunicativa. Tiene que poseer un lenguaje amplio, rico y variado. Tiene que ser capaz de escuchar a todos, de comprender a todos, de organizar sus ideas de la manera más clara y precisa; tiene que ser capaz de expresar su mensaje del modo más sencillo y natural, para que todos lo entiendan. Si no hay comunicación no hay liderazgo.

Muchas personas creen que existen dos clases de líderes: autoritarios y democráticos. Esta clasificación es errónea. Los autoritarios no son líderes sino caudillos porque carecen de humildad para aprender, no son capaces de ser empáticos y solidarios. No inspiran respeto, sino temor. Los líderes no solo son respetados, sino respetables. Son personas que inspiran confianza y afecto. Por eso, siempre los líderes son democráticos.

\section{Forjar el futuro: un prestigio profesional.}

Como manifiesta (Chiroque, s.f.): “necesitamos construir una sociedad de calidad y, para ello, se necesita tener una educación de calidad, la cual será imposible sin maestros de calidad" (p. 22). ¿Por qué? Porque el maestro o la maestra cumple un rol muy importante en el desarrollo social. Y no es correcto continuar creyendo que la educación solo sale de la casa y no de la escuela, en que la educación es producto solo de la influencia de los padres de familia y no de los docentes; sino entender que la educación de calidad sale de la institución educativa de calidad, como resultado de la actividad profesional de los (as) maestros (as); puesto que ellos (as) son los únicos profesionales que forman personas y con ellas forjan el futuro. La historia demuestra que no hemos avanzado preparándonos para el futuro, sino forjándolo a partir de la comprensión y transformación del presente, a la luz de la lección del pasado y según las demandas del desarrollo social, siempre bajo la batuta de un (a) maestro (a). Y los (as) maestros (as), a lo largo de la historia, no siempre han ostentado título profesional, sino una prodigiosa capacidad de liderazgo; por eso los hombres somos forjadores de la historia y productos de ella (Merani, 1982, p. 10).

¿Quién es el maestro o la maestra de calidad? Aquel profesional con liderazgo en la educación, preparado científica, humanística y tecnológicamente para generar una educación de calidad que nos permite forjar un futuro mejor. Poseer una preparación científica significa conocer el desarrollo de la realidad objetiva en toda su amplitud, profundidad y esencia, especialmente el origen y desarrollo filogenético y ontogenético del hombre, de manera transdisciplinaria, asumiendo la investigación científica como una actividad permanente. Estar preparado humanísticamente significa poseer una alta sensibilidad social para entender que las relaciones sociales son las condiciones imprescindibles del desarrollo de la personalidad de los educandos, porque nadie nace ni puede nacer ni desarrollarse al margen de la sociedad. $Y$ poseer una formación tecnológica significa poseer la capacidad de convertir los conocimientos científicos en estrategias de acción educativa que permita, a través de la información y el desarrollo de la personalidad de los educandos, generar una educación de calidad. 


\section{¿Qué es una educación de calidad?}

Es una educación que forma y desarrolla la personalidad de los educandos, a partir de una gestión educativa de calidad que aprovecha adecuadamente la correlación de los factores constitutivos y constituyentes del proceso educativo, para que sus egresados constituyan y fortalezcan una sociedad de calidad.

¿Qué significa formar y desarrollar la personalidad de los educandos? Facilitar todas las condiciones necesarias al educando para que se encuentre consigo mismo a partir de la convivencia con los otros; esto es, que descubra su diferencia personal y todas sus potencialidades humanas. Aquel que no se conoce a sí mismo, carece de autoestima y su vida padece de acomplejamientos. Unas veces padece de complejos de superioridad y, otras, veces de inferioridad. No se acepta a sí mismo, acude a la mentira para encubrir sus errores y convierte la hipocresía en su condición de vida. Educar es liberar al educando de todas las ataduras mentales. Desarrollar su personalidad significa desarrollar sus capacidades cognitivas, afectivas y volitivas. Desarrollar sus capacidades cognitivas y mentales implica facilitar la conversión de sus conocimientos sensoriales en conocimientos racionales, encausando acertada y oportunamente el desarrollo de todos sus procesos cognitivos y mentales. Desarrollar sus capacidades afectivas significa elevar sus sentimientos de sobrevivencia hacia los sentimientos sociales de carácter ético y estético; y, desarrollar sus capacidades volitivas o conativas implica ayudarlos a convertir sus sueños de futuro en proyectos de vida que den sentido a su destino y a toda su actividad social; pues nadie estudia para vivir según el azar.

¿Cuáles son los factores constitutivos del proceso educativo? Son los objetivos, contenidos, estrategias, recursos e indicadores de evaluación y los dos actores fundamentales del proceso educativo (maestro y educando). Para que la educación resulte ser de calidad, el enfoque del proceso educativo, la naturaleza y la correlación de estos elementos constitutivos son esenciales. Si los objetivos del proceso educativo, hoy conocido como competencias, no están orientados al desarrollo de la personalidad del educando, como hasta hoy en día se constata, no tendremos una educación de calidad. Para que la educación resulte ser de calidad, tiene que ser una educación científica. Sin embargo, es muy importante diferenciar la educación científica de la transmisión de la información científica, no porque se enseña a los educandos las disciplinas científicas de Matemática, Química, Física, Biología o Ciencias Sociales, la educación ya es de por sí científica. ¡No! La educación es científica porque se sustenta en la Pedagogía, porque esta es la ciencia de la educación. Solo el enfoque antropocéntrico que conciba al desarrollo humano como un proceso dialectico de carácter multifactorial, puede posibilitar una adecuada correlación de los factores constitutivos del proceso educativo, como un factor determinante de una educación de calidad.

¿Cuáles son los factores constituyentes del proceso educativo? La realidad económica, social, política, cultural, científica, tecnológica y lingüística. Todo proceso educativo se desarrolla en el contexto de la interacción de estos factores constituyentes. La debilidad o la vulnerabilidad, así como el olvido o la exageración de la incidencia de alguno de estos factores, dificultan el normal desarrollo del proceso educativo impidiendo lograr sus propósitos. Sin recursos económicos, obviando las demandas sociales y políticas, soslayando el carácter multicultural de nuestra sociedad y la necesidad de la interculturalidad, sustituyendo el avance científico y tecnológico con la especulación teorética, dejando de lado los avances científicos de la lingüística, es imposible conseguir una educación de calidad. Sin embargo, los factores constituyentes no determinan el proceso educativo, sino solo influyen en él. 
¿Cómo lograr que los factores constitutivos actúen positivamente sobre los factores constituyentes? ¡Allí el problema! Para que la educación logre ser de calidad, para que la sociedad del futuro logre ser de calidad, es una necesidad esencial que los factores constitutivos transformen a los factores constituyentes del proceso educativo. Los factores constitutivos dependen, fundamentalmente, de la capacidad profesional e intelectual de los docentes y directivos de la institución educativa; mientras que los factores constituyentes, por provenir de una sociedad organizada, dependen de la capacidad intelectual y política de las autoridades del gobierno local, regional y nacional. Si ambos actores del proceso educativo: unos con poder social y responsabilidad profesional (docentes y directivos) y otros con poder político y responsabilidad social (las autoridades) han de ignorar al desarrollo del ser humano como un factor determinante del desarrollo de la sociedad y no han de atender las necesidades educativas de la población como corresponde, es imposible conseguir una educación de calidad y forjar una sociedad desarrollada. No basta con que las autoridades locales, regionales o nacionales provean de infraestructura educativa, implementen con material bibliográfico a las bibliotecas, de instrumentos y de insumos a los laboratorios de las instituciones educativas, para que mejore la educación; sino es una demanda que las autoridades asuman el liderazgo en la conversión de la anomia social en una sociedad educadora, para que todo aquello que se logre en la institución educativa no se desvanezca en la sociedad, bajo el imperio de la informalidad, la frustración y el desencanto, que no son sino los perniciosos indicadores de la nefasta corrupción.

¿Qué es una sociedad de calidad? Es una sociedad educada y educadora, económicamente productiva; políticamente democrática y culturalmente que posee y desarrolla su identidad, sin complejos de ninguna clase, además de ser una sociedad equitativa, libre y justa.

Como ya señaló Sigfredo Chiroque Chunga, no es posible que haya una sociedad de calidad sin una educación de calidad y esta es imposible sin maestros de calidad; por el que la esencia de la labor del maestro o maestra es generar una educación de calidad que permita la construcción de una sociedad de calidad. Esto significa que la institución educativa es el laboratorio más hermoso que se haya conquistado a lo largo de la historia para forjar el futuro de la sociedad. Y forjar este futuro significa transformar las condiciones de la vida actual, para generar las condiciones deseadas que permita que la vida futura sea mejor, más humana y, radicalmente, diferente a la vida actual, articulando dialécticamente la teoría y la práctica; el desarrollo personal y el desarrollo social; el desarrollo científico y tecnológico con el desarrollo humano; convirtiendo las instituciones educativas en centros de desarrollo humano, científico y tecnológico, en el que la vida se dignifique en función a la práctica de los valores morales como en un factor generador de confianzas e inspirador de actividades del bien común. Ojeda \& García (2007) señalan que "sin autoridad moral poco se puede hacer para ordenar y controlar dichas actividades” (p. 84) equitativa, justa, libre y democráticamente.

Y es imperativo reiterar que los títulos profesionales o los grados académicos no siempre garantizan a los que poseen que ellos sean profesionales de calidad; porque en una sociedad donde reina el mercado negro, alentado por la economía neoliberal, estos son fáciles de conseguir. $Y$ tener presente esta realidad nos permite acicatear que el aprendizaje y la vigilancia, en el cumplimiento creativo e innovador de los propósitos educativos, sea una actividad permanente, para garantizar que la calidad profesional de los docentes o de los directores se evidencie en los excelentes resultados de su desempeño laboral. Por el que el docente y el director, tienen que ser investigadores permanentes, personas en constante actualización e innovación científica, luchadores implacables contra la corrupción que mina la moral y que destruye la condición humana. De esta responsabilidad no se eximen la familia, la sociedad, 
los medios de comunicación y el Estado, porque el proceso educativo es un fenómeno social de carácter multifactorial y polidimensional.

El rol del maestro y la maestra es organizar, critica y creativamente, estos factores, tomando en cuenta sus dimensiones, para generar las condiciones adecuadas a la formación y el desarrollo de la personalidad de los educandos; pues, para cumplir con esta misión es lo que se han formado en las instituciones de formación docente y por eso son trabajadores profesionales en la educación. El maestro o la maestra no es un sujeto cualquiera que está solo presente en el proceso educativo.

Sin embargo, no es fácil conseguir maestros de calidad en medio de las condiciones de vida que no son de calidad. ¿Cómo puede ser maestro o maestra de calidad con la miseria que gana y que no le alcanza para nada? ¿Cómo puede ser maestro de calidad si todos le tratan con menosprecio como si ocupara el último lugar en toda la jerarquía profesional? ¿Es justo y correcto que, la sociedad y el Estado, le exijan resultados de calidad, sin brindar condiciones de calidad de vida? Esto es condenar a la extinción profesional empujando a la corrupción o a la deserción laboral.

Frente a esta situación, es necesario tener presente, que el maestro no se puede ser maestro de calidad si no defiendes sus derechos, si no defiende los derechos de sus educandos y de la comunidad que le brinda una institución educativa donde laborar. Un maestro de calidad es quien defiende sus derechos y los de su comunidad, porque sabe que sus vidas son simbióticas. El desarrollo de la comunidad se sustenta en el aporte educativo de los maestros de su institución educativa y, si la comunidad no se desarrolla, es un indicador de que en ella no hay maestros y, en vez de él, que solo hay unos simples instructores o profesores.

Por eso es insoslayable diferenciar la mera transmisión de informaciones que se dan en las instituciones educativas con la actividad que forja el futuro. Cualquiera puede transmitir la información. Solo las personas preparadas, científica y tecnológicamente, los que son capaces de conducir, consciente y responsablemente, su destino y el de los demás, pueden forjar el futuro. Esta misión no es fácil, ni es simple. Es una tarea complicada, difícil, que demanda compromiso profesional y un sustento científico y tecnológico, además de una base económica. Solo el conocimiento científico de la realidad permite generar una determinada tecnología para transformar dicha realidad. Esto significa, desde el punto de vista pedagógico, comprender que los seres humanos somos el resultado de toda nuestra interacción social y productiva y que en estos procesos dinámicos interactúan la teoría y la práctica. Lo que quiere decir que para forjar el futuro hay que ser un infatigable investigador, creativo e innovador, capaz de humanizar todo lo que es posible de nuestro contexto.

Esto significa que el maestro tiene que saber convertir sus conocimientos transdisciplinarios en estrategias pedagógicas para formar y desarrollar la personalidad de los educandos., tiene que asumir ese rol con amor, responsabilidad y creatividad. Es verdad que en nuestro país hay suficiente cantidad de docentes titulados. Pero no son maestros. Solo la formación continua, en el mismo trajín de la acción pedagógica, permitirá que los docentes se conviertan en maestros y que logren una educación y una sociedad de calidad, forjando un futuro de calidad.

El maestro es la persona quien prepara a los ciudadanos del futuro y no a los ciudadanos del pasado. ¿Esto significa que el maestro conoce el futuro? ¡No! El maestro forma en los educandos y con ellos el futuro. ¿Esto significa que el pasado no le importa? ¡No! El pasado le importa en la medida en que lo provee de lecciones para encontrar las causas del presente y 
las estrategias para enrumbar el futuro. El maestro enseña al educando a transformar la información en conocimiento, en sabiduría, en poder y libertad. El maestro es quien desarrolla la capacidad crítica y creativa de los educandos, su capacidad ética y moral, empleando acertada y selectivamente la información.

\section{Conclusión}

Las condiciones en las cuales se desarrolla la educación en nuestro país no es la más adecuada; ni estas condiciones a las cuales pretende responder no es la más estable; por eso el sistema educativo que emana de esta realidad, en vez de formar y desarrollar la personalidad de los educandos, está condenado a reproducir solamente su referente inmediato y a expresarse como crisis educativa. En el contexto de esta situación urge revelar y entender, como un factor esencial de la calidad educativa (aspiración de todos), la formación continua de los maestros y maestras del país.

Es imposible convertir la crisis educativa en creces educativa sin transformar a los docentes en trabajadores profesionales en la educación; es decir, en maestros líderes. Y esto implica superar muchos mitos; entre ellos, el de la edad y de la ubicación geográfica. Pues muchos docentes creen que la vejez es un impedimento para continuar en la actualización y especialización profesional e intelectual, ignorando que los problemas de Alzheimer o de Parkinson son solo productos de la inactividad intelectual, física o de los accidentes cerebrales y no indicadores absolutos de la senectud; pues muchos profesionales han muerto en plena actividad cerebral. Y tampoco es cierto que la zona rural de por sí condena al maestro o maestra a vegetar intelectualmente. ¿Acaso ignoramos la biografía de Jerome Bruner? Escribió él: “deseaba pasar un verano tranquilo ordenando mis ideas. Abandoné Nueva York con dos maletas, una con ropa y otra con libros. Me interné todo lo que pude en la Cordillera Lurentiana, busqué un lugar tranquilo y encontré una familia que me ofreció alojamiento durante un mes. Allí leí, investigué y sistematicé todo lo que pude" (Bruner, 2004, p. 219).

Y el otro mito que debe ser desterrado es la creencia de que existen maestros y maestras mal formados; porque no hay maestros y maestras mal formados. El maestro o maestra es una personalidad bien formada y bien desarrollada y que está en capacidad de formar y desarrollar la personalidad de los educandos. Esto significa que no todo docente es maestro; pues para serlo tiene que estar en formación continua, por ser una condición necesaria para lograr una educación de calidad; lo que quiere decir que el maestro no es sinónimo de instructor o de profesor, como ya dijimos líneas arriba. Y la educación será de calidad solo cuando responda a nuestras múltiples necesidades y demandas personales, familiares, sociales y laborales y cuando nos ubique, como país, en una situación relevante en el contexto internacional en lo económico, político y cultural, como resultado de la transformación de nuestras materias primas en productos industrializados.

Un maestro (o maestra) de calidad tiene una visión de futuro y es capaz de comprender y humanizar todo cuanto le rodea, no con una retórica gratuita, sino con el ejemplo, investigando y actuando sobre la realidad, creativa e innovadoramente, según los escenarios en los cuales le corresponde laborar. Es consciente de que los escenarios educativos no son homogéneos. Sabe que entre lo urbano y lo rural hay una diferencia cualitativa y que cada uno de ellos presentan múltiples situaciones problemáticas, con demandas de soluciones también distintas. Sabe que la educación rural está en crisis, no porque los niños y las niñas sean menos inteligentes que sus pares citadinos, sino porque la educación urbana no responde a la natu- 
raleza específica del desarrollo del mundo rural, al omitir su diversidad geográfica, socioeconómica, política, lingüística, cultural e histórica. Por eso, en vez de contribuir al desarrollo de su cultura local, la destruye en nombre del progreso; desplazando la capacidad productiva de la población con el consumismo alienante, convirtiendo las instituciones educativas en formadora de éxodos masivos; a pesar de que estas instituciones educativas fueron creadas por las comunidades para conseguir su desarrollo y no para huir de sus problemas. El maestro es consciente de esta realidad y sabe que los problemas de la educación rural no pueden ser resueltos por los especialistas de la educación urbana; ni los problemas de la educación urbana, por los especialistas de la educación rural.

De allí que la formación continua de los docentes en el mismo proceso de la investigación pedagógica es una necesidad impostergable para sacar la educación de nuestro país del sótano en el que se encuentra. Solo la investigación y la producción de conocimientos pedagógicos, rigurosamente actualizados según la problemática de cada contexto, podrá garantizarnos elevar los estándares del desempeño profesional de nuestros docentes. El maestro sabe que todo auténtico proceso educativo consiste articular las diferencias culturales y lingüísticas en una complementariedad humana de carácter intercultural con apertura democrática, en el que todos aprendan de todos, donde no haya espacio para los opresores ni los oprimidos, sino solo para la comunión humana en el que la justicia no sea un mito sino una realidad.

\section{Referencias bibliográficas}

Arguedas, J. (1986). Nosotros los Maestros. Lima: Horizonte.

Bruner, J. (2004). El Desarrollo Cognitivo y Educación. Madrid: Morata, Quinta Edición.

Chiroque, S. (s.f.). Organización Nuclear de los Docentes y Formación Continua. Plabra del Maestro $\mathrm{N}^{\circ} 42$.

Crisólogo, J. (1995). La Cantuta, formadora de maestros. La Cantuta, 63.

Delors. (1997). El Personal Docente en busca de Nuevas Perspectivas. Revista de Educación y Cultura $N^{\circ} 40,26-27$.

Merani, A. (1982). Psicología Genética. México: Grijalbo.

Ojeda, L., \& García, F. (2007). Una Alternativa Amazónica de Formación Docente. Lima: Foro Educativo: Congreso Internacional.

Sanmartín, O. (2015). Los cinco grandes problemas del profesorado español. Obtenido de https:// www.elmundo.es/sociedad/2015/11/03/5637c9dc268e3e02488b456c.html

Tenti, E. (2005). La Profesionalización de los docentes. Una mirada a Argentina, Brasil, Uruguay y Perú. Palabra del Maestro, $N^{\circ} 42$.

Vigotsky, L. (1979). El desarrollo de los procesos psicológicos superiores. Obtenido de https:// saberespsi.files.wordpress.com/2016/og/vygostki-el-desarrollo-de-los-procesospsicolczb3gicos-superiores.pdf

Wiener, R. (2011). Reflexiones sobre el caso Ciro. Obtenido de http://rwiener.blogspot.com/2011/10/ el-director-del-periodico-serio-que-mas.html

(C) Los autores. Este artículo es publicado por la Horizonte de la Ciencia de la Unidad de Posgrado de la Facultad de Educación de la Universidad Nacional del Centro del Perú. Este es un artículo de acceso abierto, distribuido bajo los términos de la Licencia Atribución-No Comercial 4.0 Internacional.(https://creativecommons.org/licenses/by-nc/4.o/), que permite el uso no comercial y distribución en cualquier medio, siempre que la obra original sea debidamente citada. 